\title{
Risk Factors for Middle East Respiratory Syndrome Coronavirus Infection among Camel Populations, Southern Jordan, 2014-2018
}

\author{
Peter Holloway, Matthew Gibson, Neeltje van Doremalen, Stephen Nash, \\ Tanja Holloway, Michael Letko, Jacqueline M. Cardwell, Bilal Al Omari, Ahmad Al-Majali, \\ Ehab Abu-Basha, Punam Mangtani, Vincent J. Munster, Javier Guitian
}

\begin{abstract}
After the first detection of Middle East respiratory syndrome coronavirus (MERS-CoV) in camels in Jordan in 2013, we conducted 2 consecutive surveys in 2014-2015 and 2017-2018 investigating risk factors for MERS-CoV infection among camel populations in southern Jordan. Multivariate analysis to control for confounding demonstrated that borrowing of camels, particularly males, for breeding purposes was associated with increased MERSCoV seroprevalence among receiving herds, suggesting a potential route of viral transmission between herds. Increasing age, herd size, and use of water troughs within herds were also associated with increased seroprevalence. Closed herd management practices were found to be protective. Future vaccination strategies among camel populations in Jordan could potentially prioritize breeding males, which are likely to be shared between herds. In addition, targeted management interventions with the potential to reduce transmission between herds should be considered; voluntary closed herd schemes offer a possible route to achieving disease-free herds.
\end{abstract}

$\mathrm{M}$ iddle East respiratory syndrome (MERS) coronavirus (MERS-CoV) represents 1 of 3 major zoonotic coronaviruses to have emerged with global impact in the past 2 decades, alongside severe acute

Author affiliations: The Royal Veterinary College, Hatfield, UK (P. Holloway, J.M. Cardwell, J. Guitian); Glasgow University, Glasgow, Scotland, UK (M. Gibson); National Institute of Allergy and Infectious Diseases, National Institutes of Health, Hamilton, Montana, USA (N. van Doremalen, M. Letko, V.J. Munster); London School of Hygiene and Tropical Medicine, London, UK (S. Nash, T. Holloway, P. Mangtani); Jordan University of Science and Technology, Irbid, Jordan (B. Al Omari, A. Al-Majali, E. Abu-Basha)

DOI: https://doi.org/10.3201/eid2709.203508 respiratory syndrome coronavirus (SARS-CoV-1) in 2002-2003 and severe acute respiratory syndrome coronavirus 2 (SARS-CoV-2) from 2019 onward (1). The earliest known outbreak of MERS-CoV began in a hospital in Zarqa, Jordan, in April 2012 (2,3). Since that time, $>2,500$ cases and 880 deaths (case-fatality rate of $34 \%$ ) have been reported across 27 countries worldwide (4). The first detection of positive MERS$\mathrm{CoV}$ by serologic testing in camels was also from Zarqa, Jordan, in 2013 (5); camels were later confirmed as the reservoir for MERS-CoV infection in humans (6) and bats the likely ancestral host (7).

Most confirmed MERS-CoV cases have occurred within the Arabian Peninsula; Saudi Arabia, the location of $\approx 80 \%$ of all human cases, is the epicenter (8). Phylogenetic analyses of viral sequences isolated from camels and humans suggest that multiple camel-to-human spillover events have occurred since the initial MERS outbreaks in 2012 (9). Although humans sometimes represent a dead-end host, secondary human-to-human infection does occur, leading in some cases to large-scale outbreaks in hospital settings, such as those seen in Saudi Arabia and South Korea in recent years $(10,11)$. Whereas infection in camels might be subclinical or cause mild upper respiratory symptoms $(12,13)$, infection in humans can range from asymptomatic to severe acute respiratory disease or death (14).

The World Health Organization has declared MERS-CoV a priority disease in its Research and Development Blueprint program as a public health risk of epidemic potential (15); vaccination of camels is a potential key component of future disease control strategies (16). Although MERS-CoV is widespread among camel populations in Africa, the Middle East, 
and South Asia, its epidemiology within these populations remains poorly understood, particularly with regard to viral transmission routes and risk factors for infection (17). Such knowledge is urgently needed if camel vaccines currently in development are to be deployed effectively (18-21) and if management interventions with the potential to contribute to disease control are to be identified. We addressed these key knowledge gaps through 2 large-scale, consecutive epidemiologic surveys among camel populations in southern Jordan, close to the border of Saudi Arabia.

\section{Methods}

\section{Study Design and Study Population}

We conducted 2 distinct studies during February 2014-December 2015 and October 2017-October 2018. Both studies were conducted in Aqaba and Ma'an governorates of southern Jordan, an area with $\approx 8,000$ camels (according to Jordanian Ministry of Agriculture [MoA] data) and $550 \mathrm{~km}$ of desert border with Saudi Arabia to the south and east (Figure 1).

In the 2014-2015 study, because of the absence of an adequate sampling frame, we conducted nonprobabilistic sampling among clients of a centrally located private veterinary practice in Al Quwayrah (Aqaba governorate). During the study period, the $\mathrm{Al}$ Quwayrah clinic closed (February 2015); the final 53 herds included in the study were recruited through local contacts of government veterinarians working in the study area. We collected serum samples from the onset, whereas collection of nasal swab specimens began in March 2015 and occurred in the final 53 herds only.

In the 2017-2018 study, we conducted multistage cross-sectional random sampling by using MoAsupplied lists of camel owners for Aqaba and Ma'an governorates organized by 4 local administrative areas (Aqaba East, Aqaba West, Ma'an East, and Ma'an West). We collected serum samples and nasal swab specimens from the onset.

In both studies, to encourage owner compliance, we sampled $\leq 12$ camels per herd; in herds of $<12$, we sampled all camels, subject to accessibility and owner permissions. A structured questionnaire regarding potential risk factors for MERS-CoV infection was administered in the local dialect on paper (2014-2015 study) or on Android tablets using the application Open Data Kit (2017-2018 study) (https://getodk. org) to herd owners face-to-face at the time of sampling or by telephone after sampling. A veterinary surgeon clinically examined all camels included in the study to assess general health before sampling.

\section{Sample Storage and Laboratory Methods}

Blood samples were collected in $8 \mathrm{~mL}$ serum vacutainer tubes and centrifuged at 2,000 RPM for $10 \mathrm{~min}$, followed by serum collection and storage at $-20^{\circ} \mathrm{C}$. Nasal swab specimens were placed in viral transport medium and chilled before storage at $-20^{\circ} \mathrm{C}(2014-2015$

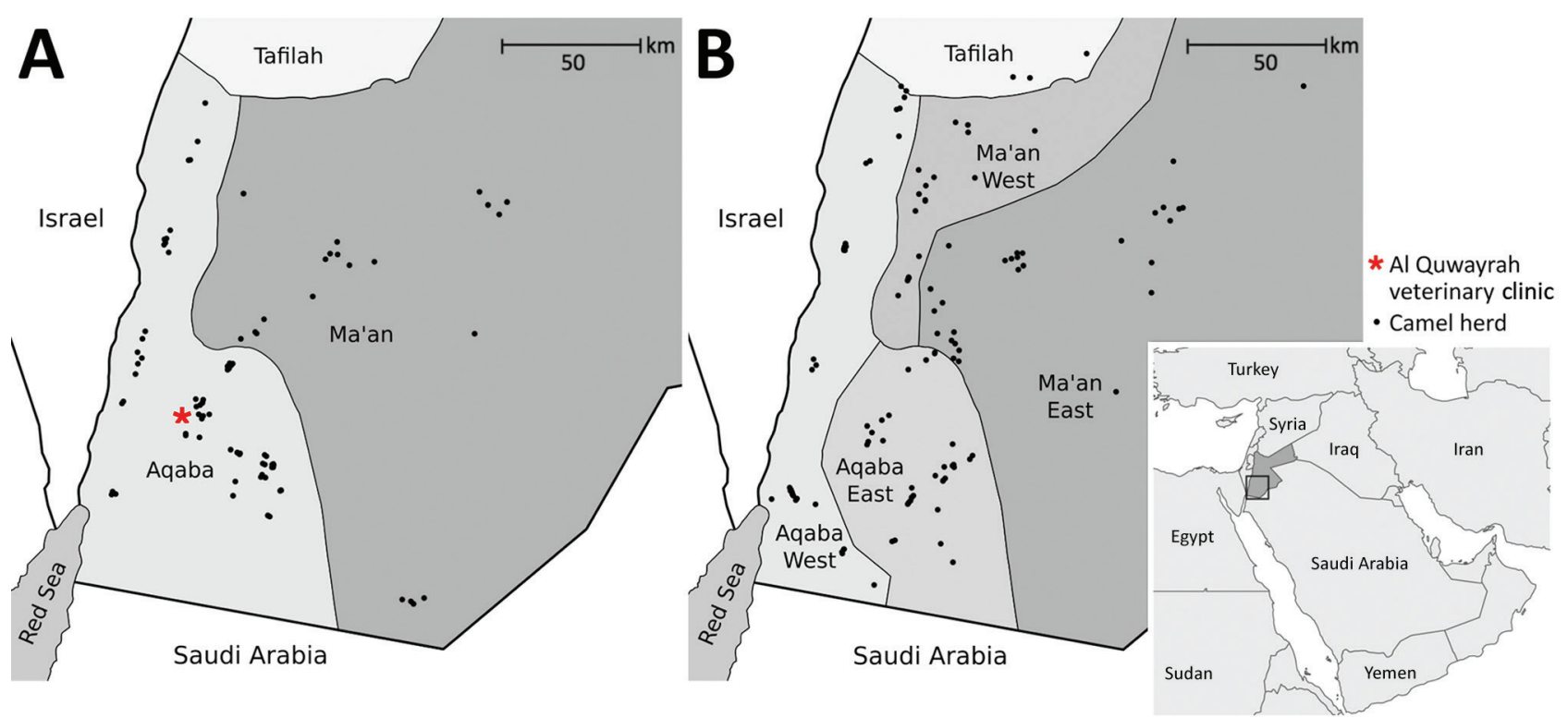

Figure 1. Location of camel herds sampled for Middle East respiratory syndrome coronavirus in southern Jordan, February 2014December 2015 and October 2017-October 2018. A) 2014-2015 study; B) 2017-2018 study. Samples were taken from camels from 97 herds in the 2014-2015 study and from 121 herds in the 2017-2018 study. In the 2017-2018 study, because of local grazing movements, 3 herds selected from the Jordanian Ministry of Agriculture list for Ma'an West were sampled in the neighboring region, Tafilah, and results from these herds attributed to Ma'an West. 
study) or $-80^{\circ} \mathrm{C}(2017-2018$ study). All laboratory testing of samples was performed at the Diagnostic Laboratory, Veterinary Health Centre, Jordan University of Science and Technology (Irbid, Jordan).

\section{ELISA}

We tested serum samples in duplicate by using a MERS-CoV spike protein ELISA as previously described by van Doremalen et al. (22). In brief, maxisorp plates were coated overnight with S1 protein (Sino Biological, https://www.sinobiological.com) before blocking with $1 \%$ milk. MERS-CoV S1-specific antibodies were detected by using anti-llama IgG horseradish peroxidase-conjugated antibodies (Agrisera, https://www.agrisera.com) and subsequently developed with peroxidase-substrate reagent (KPL). Optical densities were measured at $405 \mathrm{~nm}$ and positivity at 3 times mean negative camel serum samples collected from United States-bred dromedary camels confirmed to be MERS-CoV-free. This assay does not cross-react with antibodies to bovine coronavirus, OC43, or SARS-CoV-1 (23).

\section{Viral RNA Extraction and MERS-CoV Detection}

RNA was extracted from nasal swab specimens by using the QiaAmp Viral RNA kit (QIAGEN, https:/ / www.qiagen.com) according to the manufacturer's instructions $\leq 18$ months after sample collection. Extracted RNA was used in a 1-step real-time reverse transcription PCR (rRT-PCR) UpE MERS-CoV assay performed on a QIAGEN Rotor-Gene instrument, with positivity set at a cycle threshold value of $<40$, on the basis of standard operating procedures as described in Corman et al. (24).

\section{Statistical Analysis}

In each study, we separately calculated seroprevalence estimates weighted according to sample size relative to the estimated camel population (based on MoA data) and ran regression models for identification of risk factors. Because of the differences in sampling strategy, weighting was conducted by region for the 2014-2015 study and by subregion for the 2017-2018 study. In both studies, we excluded camels $\leq 6$ months of age from analyses because of the potential influences of maternally derived immunity.

We conducted univariate analyses by using mixed-effects regression with herd as a random effect and camel serologic status considered a binary outcome. All potential risk factors were analyzed as categorical variables, with the exception of camel age and herd size, which were analyzed as continuous variables. Variables were herd level with the exception of age, sex, racing camel, and nasal discharge. For the 2017-2018 study (data were missing in the 2014-2015 study), we constructed a composite variable "closed herd," which we defined as herds in which no borrowing, lending, purchasing, racing, or contact with local or distant herds occurred.

We considered variables with a $p$ value of $<0.2$ for inclusion in the multivariate models, with the exception of any variables missing $>10 \%$ of their values. We used the Pearson R coefficient and a threshold of 0.4 to compare collinearities between variables; we excluded colinear variables from the same multivariate model and tested in separate models. We conducted multivariate models by using mixed-effects regression with herd as a random effect and constructed using a backward stepwise method, removing the least significant variable at each step while $p>0.1$, unless the variable was considered an a priori factor (region, sex, and age) or the removal of the variable demonstrated a significant effect on the other variables (a change in log odds of $>10 \%$ ). We repeated model creation by using a forward stepwise method, beginning with a priori variables and adding new variables in order of significance, keeping variables if they showed significance of $p<0.1$ or changed the log odds of other risk factors by $>10 \%$. We performed all statistical analyses in $R$ version 3.5.1 (https:/ / cran.rproject.org) and generated mixed-effects models by using the glmer function of the R package lme4 version 1.1-21.

\section{Ethics Statement}

Informed consent was obtained from all participating camel owners at the time of sampling, and institutional and national guidelines for care, use, and handling of animals were followed at all times. Studies were conducted with institutional review board approval by the Royal Veterinary College and London School of Hygiene and Tropical Medicine, National Institute of Allergy and Infectious Diseases, and Jordan University of Science and Technology and MoA.

\section{Results}

\section{Study Results for 2014-2015}

For 2014-2015, we included 433 camels with a median age of 6 years (interquartile range [IQR] 3-9 years) representing 97 herds (median herd size 11 [IQR 5-22]). We obtained blood samples from an average of 4.5 camels/herd and collected nasal swab specimens from $65 \%$ of included camels. The questionnaire was completed for 93 of 97 herds; we excluded 4 herds (17 camels) that lacked questionnaire data from the 
analysis of risk factors. A total of 21 questionnaires were completed at the time of sampling, and 72 were completed subsequently by telephone.

In total, 128 sampled camels (from 22 herds) were from Ma' an region and 305 (from 75 herds) were from Aqaba region. MoA records indicated an estimated population of 4,436 camels (317 herds) in Ma'an region and 3,314 camels (265 herds) in Aqaba region; we weighted adjusted seroprevalence accordingly. Of 433 camels sampled, 381 were seropositive for MERS$\mathrm{CoV}$, an unadjusted seroprevalence of $88.0 \%$ and adjusted seroprevalence of $86.8 \%$ (95\% CI 82.8-90.3). Of these, 9 camels were $\leq 6$ months of age, of which 4 were seropositive $(44.4 \%)$. After we excluded these calves from the dataset, the adjusted seroprevalence was $88.0 \%$ (95\% CI 84.1-91.4). No nasal swab specimens tested positive for MERS-CoV RNA on rRTPCR.

Of 97 herds sampled, 93 had $>1$ seropositive camel (including calves $<6$ months of age), resulting in an unadjusted herd-level seroprevalence of 95.9\% and adjusted herd-level seroprevalence of 92.3\% (95\% CI 83.3-97.1); median herd sample seroprevalence was 100\% (IQR 80\%-100\%) (Figures 2, $3)$. Highest weight-adjusted seasonal seroprevalence was in summer (93\%) and lowest was in fall (84\%); winter and spring results were both $88 \%$.

In univariate analysis, age, sex, herd size, number of herds nearby, quarantine $>3$ days after purchase, borrowing of breeding males, and water source were all found to be associated with seropositivity at $p<0.2$, although we identified no significant correlations for these variables (Table 1, https:// wwwnc.cdc.gov/EID/article/27/9/20-3508-T1. htm; Table 2; Figures 4, 5). Quarantine was excluded from the multivariate models because of a high number of missing values $(62 \%)$.

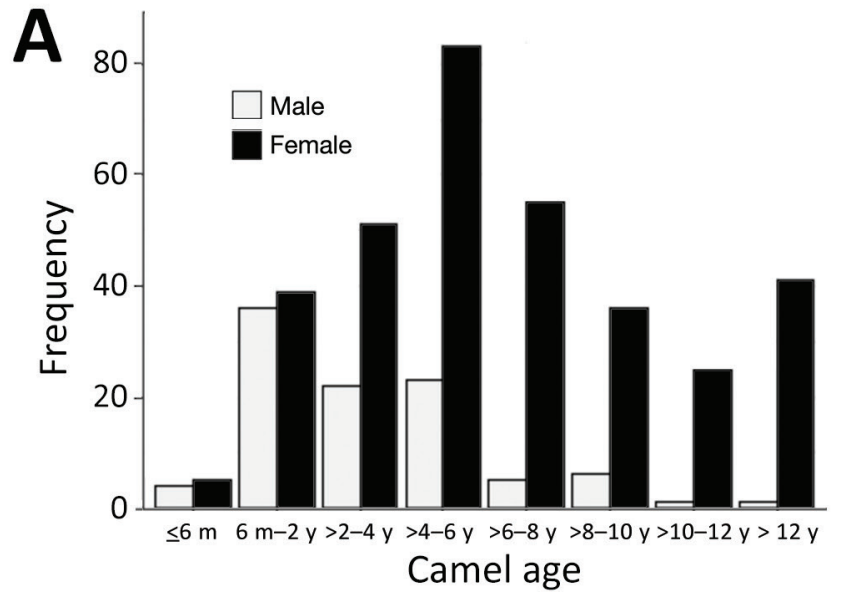

Figure 2. Frequency distribution of camels sampled for Middle East respiratory syndrome coronavirus in southern Jordan, February 2014-December 2015 and October 2017-October 2018, stratified by age. A) 2014-2015 study; B) 2017-2018 study.
Variables in the final multivariate model results were age, herd size, borrowing of males for breeding purposes, and water source (Table 3). We noted evidence of an association between camel seropositivity and borrowing of males for breeding purposes (adjusted OR [aOR] 4.18 (95\% CI 1.45-12.09); p = 0.01), age per year (aOR 1.24 [95\% CI 1.08-1.42]; $\mathrm{p}<0.01$ ), and herd size per additional camel (aOR 1.04 [95\% CI 1.01-1.08]; $\mathrm{p}=0.02$ ).

\section{Study Results for 2017-2018}

Blood samples and nasal swab specimens were collected from 404 camels (median age 5 years [IQR 3-8 years]) in 121 herds; an average of 3.3 camels were sampled per herd (median herd size 9 [IQR 4-17]). The questionnaire was administered to all 121 herd owners; 114 questionnaires were completed at the time of sampling, and 7 were completed subsequently by telephone. In total, 90 camels ( 29 herds) were sampled from Ma'an East, 70 (21 herds) Ma' an West, 152 camels (36 herds) from Aqaba East, and 92 (35 herds) from Aqaba West. MoA records described an estimated 1,909 camels (138 herds) in Aqaba East, 1,405 camels (127 herds) in Aqaba West, 3,563 camels (198 herds) in Ma'an East, and 873 camels (119 herds) in Ma'an West; we weighted adjusted seroprevalence accordingly.

Of 404 camels sampled, 264 were seropositive for MERS-CoV, for an unadjusted seroprevalence of $65.3 \%$ and an adjusted seroprevalence of $70.2 \%$ (95\% CI 65.6-74.7). Of these, 26 of 39 camels $\leq 6$ months of age were seropositive $(66.7 \%)$, which compares with $18(22.8 \%)$ of 79 among camels $>6$ months -2 years of age (OR 20.8 [95\% CI 4.8-226.3]; p<0.01). After removal of calves $\leq 6$ months from the dataset, the adjusted seroprevalence was $70.2 \%$ (95\% CI 65.0-75.2) among 119 herds.

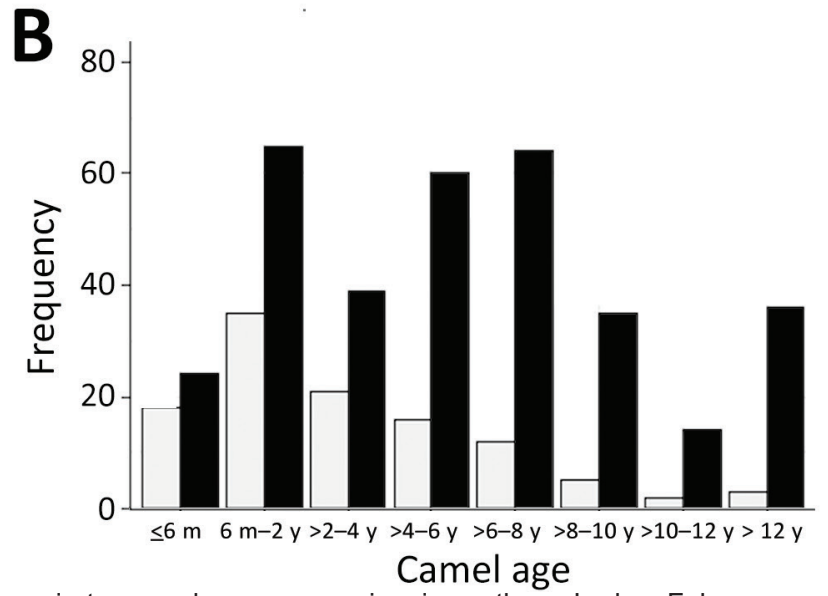


Table 2. Univariate associations between potential risk factors and Middle East respiratory syndrome coronavirus seropositivity in camel populations, Jordan, February 2014-December 2015 and October 2017-October 2018*

\begin{tabular}{|c|c|c|c|c|}
\hline \multirow[b]{2}{*}{ Variable } & \multicolumn{2}{|c|}{ 2014-2015 study } & \multicolumn{2}{|c|}{ 2017-2018 study } \\
\hline & OR $(95 \% \mathrm{Cl})$ & $p$ value & OR $(95 \% \mathrm{Cl})$ & p value \\
\hline \multicolumn{5}{|l|}{ Region } \\
\hline Aqaba & Referent & 0.53 & Referent & 0.01 \\
\hline Ma'an & $0.68(0.18-2.30)$ & & $3.95(1.42-12.85)$ & \\
\hline Age, per y† & $1.22(1.08-1.39)$ & $<0.01$ & $1.63(1.39-2.01)$ & $<0.01$ \\
\hline \multicolumn{5}{|l|}{ Sext } \\
\hline $\mathrm{F}$ & $2.48(0.90-6.70)$ & 0.07 & $3.02(1.28-7.09)$ & 0.01 \\
\hline \multicolumn{5}{|l|}{ Herd size } \\
\hline Per individual no. camels & $1.05(1.01-1.09)$ & 0.01 & $1.02(1.00-1.04)$ & 0.08 \\
\hline \multicolumn{5}{|l|}{ No. camel herds within a 15 min drive } \\
\hline$>20$ & $2.42(0.72-9.07)$ & 0.16 & $2.24(0.70-7.86)$ & 0.18 \\
\hline Herd kept together as single group throughout the year & $0.84(0.13-5.04)$ & 0.85 & $2.88(1.04-8.93)$ & 0.05 \\
\hline Herd has contact with other local herds & $1.43(0.30-6.64)$ & 0.63 & $2.97(1.07-9.17)$ & 0.04 \\
\hline Herd has contact with distant herds & $0.55(0.13-2.00)$ & 0.36 & $1.86(0.67-5.34)$ & 0.23 \\
\hline New camels are purchased $\ddagger$ & $0.77(0.19-2.94)$ & 0.70 & $1.51(0.53-4.71)$ & 0.44 \\
\hline Quarantine $>3 \mathrm{~d}$ after purchase before joining herd & $0.23(0.03-1.55)$ & 0.10 & $0.42(0.02-6.88)$ & 0.52 \\
\hline Camels borrowed for breeding purposes§ & $2.96(0.87-11.42)$ & 0.08 & $3.94(1.45-12.32)$ & 0.01 \\
\hline Herd-level b & $2.96(0.87-11.42)$ & 0.08 & NR & NR \\
\hline Herd-level borrowing of fem & $2.45(0.49-16.62)$ & 0.30 & NR & NR \\
\hline Camels loaned for breeding & NR & NR & $3.28(1.19-10.44)$ & 0.03 \\
\hline Camels in herd are used for racing & $0.49(0.07-3.26)$ & 0.44 & $0.89(0.29-2.66)$ & 0.83 \\
\hline Camel is a racing camel† & NR & NR & $0.37(0.09-1.44)$ & 0.15 \\
\hline \multicolumn{5}{|l|}{ Water source } \\
\hline Open ad lib & Referent & 0.13 & Referent & 0.15 \\
\hline Household only & $1.89(0.05-72.38)$ & & $2.81(0.59-14.25)$ & \\
\hline Trough only & $7.15(0.95-70.49)$ & & $4.07(1.01-18.88)$ & \\
\hline Spring & $0.13(0.01-0.98)$ & 0.05 & $0.20(0.04-0.80)$ & 0.03 \\
\hline Irrigation reservoir & $0.05(0.00-0.91)$ & 0.05 & $0.36(0.06-2.22)$ & 0.27 \\
\hline Tanker & $1.24(0.31-5.11)$ & 0.75 & $0.77(0.25-2.37)$ & 0.64 \\
\hline Tap & $0.82(0.20-3.94)$ & 0.78 & $0.99(0.35-2.86)$ & 0.99 \\
\hline Well & $0.57(0.08-3.57)$ & 0.54 & $0.44(0.13-1.41)$ & 0.16 \\
\hline Water source not shared with herd, household use only & $0.30(0.01-7.54)$ & 0.45 & $0.96(0.29-3.00)$ & 0.94 \\
\hline Closed herd\# & NR & NR & $0.09(0.01-0.39)$ & $<0.01$ \\
\hline \multicolumn{5}{|c|}{$\begin{array}{l}\text { *Variables reference the 1-year period before sampling, with the exception of herd size, camel is a racing camel, and a priori variables: age, sex, and } \\
\text { region. Because of the potential influence of maternal immunity, camels } \leq 6 \mathrm{~m} \text { of age have been excluded from all variables except age. NR, not recorded. } \\
\text { tIndividual camel-level variables (all other variables being herd-level). } \\
\text { fCamels purchased are locally bred; Jordanian Ministry of Agriculture Camel Import Regulations and Conditions allow import only for live camels for } \\
\text { direct slaughter. } \\
\text { \$ln the } 2014-15 \text { study, results for camels are borrowed for breeding purposes (male and/or female) and camels are borrowed for breeding purposes } \\
\text { (male) were the same (i.e., all herds that borrowed camels for breeding borrowed males, and some of these herds also borrowed females). In the } 2017- \\
18 \text { study, the sex of camels borrowed or loaned for breeding was not recorded. } \\
\text { TOpen ad lib indicates irrigation reservoir or spring water sources were used; household only indicates water source was not shared between household } \\
\text { and herd; trough only indicates only tanker, tap, or well sources were used. } \\
\# \text { \#losed herd indicates herd owners answered no to all of the following variables: borrowing, lending, purchasing, racing, and contact with local or distant } \\
\text { herds (2017-2018 study only, missing data 2014-2015). }\end{array}$} \\
\hline
\end{tabular}

Of 119 herds sampled, 92 had $>1$ seropositive camel (including calves $<6$ months of age), resulting in an unadjusted herd-level seroprevalence of $77.3 \%$ and adjusted herd-level seroprevalence of $77.0 \%$ (95\% CI 69.8-83.0); median herd sample seroprevalence was 75\% (IQR 25\%-100\%) (Figures 2, $3)$. The highest weight-adjusted seasonal seroprevalence was in spring $(75 \%)$ and the lowest in winter $(63 \%)$; seroprevalence in fall was $70 \%$ (because of logistical constraints, no samples were collected during the summer).

No nasal swab specimens tested positive for MERS-CoV RNA on rRT-PCR. Nasal discharge was noted in 8 camels $(2.6 \%$ [ $95 \%$ CI $1.4 \%-4.8 \%])$ at the time of sampling (ages 3, 5, 6, 7, 7, 12, 14 and 15 years).
In the univariate analysis, the following 12 variables were found to be associated with seropositivity at $\mathrm{p}<0.2$ : region, age, sex, herd size, number of herds nearby, herd being kept as a single group throughout the year, contact with local herds, borrowing of camels for breeding purposes, lending of camels for breeding purposes, use of camels for racing, water source, and closed herd status (Tables 1 , 2; Figures 4,5). We identified correlations between contact with local herds and lending for breeding purposes (Pearson R coefficient $=0.46$ ) and between borrowing for breeding purposes and lending for breeding purposes (Pearson $\mathrm{R}$ coefficient $=0.46$ ).

Variables in the final multivariate model results were region, sex, age, herd size, borrowing 

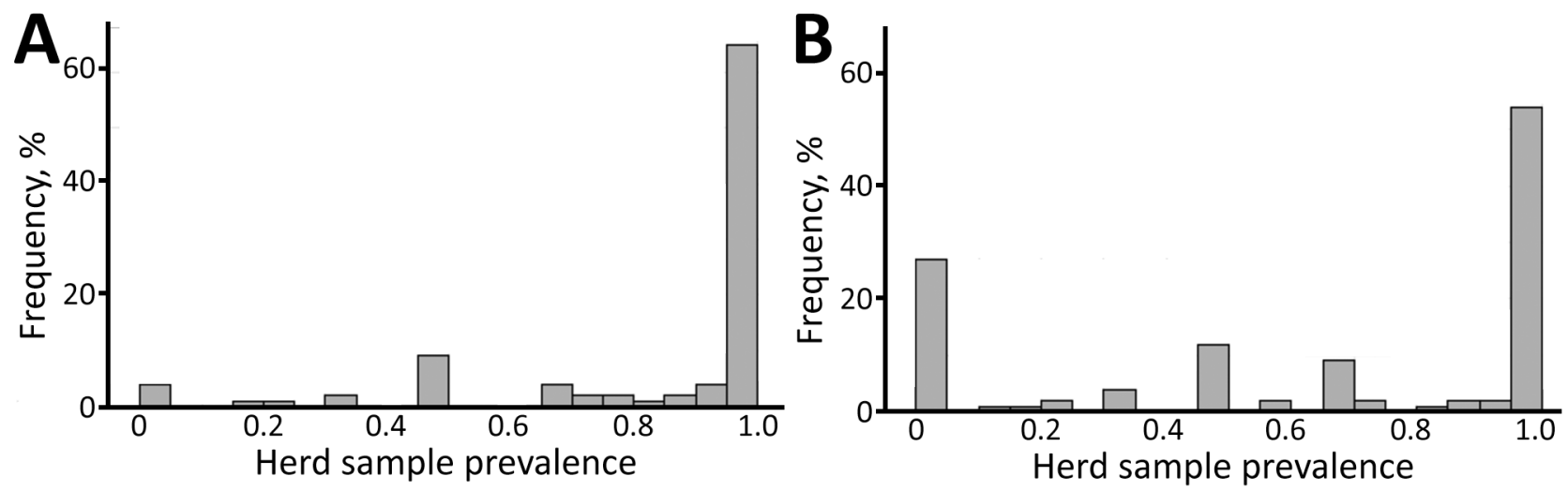

Figure 3. Frequency distribution of camel herd sample Middle East respiratory syndrome coronavirus seroprevalence, southern Jordan, February 2014-December 2015 and October 2017-October 2018. A) 2014-2015 study; B) 2017-2018 study

for breeding purposes, water source, and closed herd status (Table 4). Evidence of an association was noted between camel MERS-CoV seropositivity and drinking from water trough sources only, as compared with open ad lib sources (aOR 9.48 [95\% CI 1.54-58.24]; $p=0.05)$; borrowing camels for breeding purposes (aOR 5.07 [95\% CI 1.37-18.75]; $\mathrm{p}$ $=0.02$ ); location in Ma' an region (aOR 3.83 [95\% CI 1.01-14.51]; $\mathrm{p}=0.05)$; and increasing age per year (aOR 1.60 [95\% CI 1.34-1.92]; p<0.01). We investigated the variable of lending camels for breeding purposes in a separate model, in place of camels being borrowed for breeding purposes, but did not find evidence of a significant association with seropositivity. The composite variable closed herd demonstrated evidence of a protective association with MERS-CoV seropositivity (aOR 0.08 [95\% CI $0.01-0.55] ; p=0.02$ ) when included in a separate model adjusted for the same confounders, although excluding constituent variables for closed herd, borrowing, and lending for breeding purposes.

\section{Discussion}

Previous studies have described MERS-CoV seroprevalence among camel populations worldwide; however, substantial knowledge gaps remain, in particular with regard to factors associated with higher risk for infection, which might provide insights into viral transmission routes between and within camel herds $(16,17)$. Such knowledge is essential if effective disease control strategies, such as targeted vaccination programs and camel management interventions, are to be appropriately designed and implemented.

Our findings suggest that borrowing male camels for breeding might serve as a transmission route for

Table 3. Multivariate associations between potential risk factors and Middle East respiratory syndrome coronavirus seropositivity in camel populations, southern Jordan, February 2014-December 2015*

\begin{tabular}{|c|c|c|c|c|}
\hline Variable & A priori adjusted OR $(95 \% \mathrm{Cl}) \dagger$ & $p$ value & Fully adjusted OR $(95 \% \mathrm{Cl}) \ddagger$ & $p$ value \\
\hline Age, per y§ & $1.21(1.07-1.40)$ & $<0.01$ & $1.24(1.08-1.42)$ & $<0.01$ \\
\hline Male camels borrowed for breeding purposes & $3.44(1.09-12.25)$ & 0.04 & $4.18(1.45-12.09)$ & 0.01 \\
\hline \multicolumn{5}{|l|}{ Herd size } \\
\hline Increasing individual camel nos. & $1.05(1.01-1.09)$ & $<0.01$ & $1.04(1.01-1.08)$ & 0.02 \\
\hline \multicolumn{5}{|l|}{ Water sourceף } \\
\hline Open ad lib" & Referent & 0.19 & Referent & 0.08 \\
\hline Household only & $0.52(0.01-21.39)$ & & $0.90(0.05-16.46)$ & \\
\hline Trough only & $4.02(0.51-40.84)$ & & $4.74(0.93-24.08)$ & \\
\hline \multicolumn{5}{|l|}{ Region } \\
\hline Ma'an & $0.56(0.16-1.79)$ & 0.33 & $0.37(0.12-1.14)$ & 0.08 \\
\hline \multicolumn{5}{|l|}{ Sex§ } \\
\hline $\mathrm{F}$ & $1.35(0.45-3.86)$ & 0.58 & $1.12(0.38-3.26)$ & 0.84 \\
\hline \multicolumn{5}{|l|}{ Number of camel herds within a 15-min drive } \\
\hline$>20$ & $2.24(0.68-7.99)$ & 0.18 & - & - \\
\hline \multicolumn{5}{|c|}{$\begin{array}{l}\text { *Variables reference the 1-year period before sampling, with the exception of herd size, camel is a racing camel, and a priori variables: age, sex, and } \\
\text { region. Because of the potential influence of maternal immunity, camels } \leq 6 \mathrm{~m} \text { of age have been excluded. OR, odds ratio. } \\
\text { †Adjusted for a priori variables: age, sex, and region. } \\
\ddagger 2014-2015 \text { study was adjusted for a priori variables and number of camels nearby (within a } 15 \text { min drive). } \\
\text { §lndividual camel-level variables (all other variables being herd-level). } \\
\text { †Open ad lib indicates irrigation reservoir or spring water sources were used; household only indicates water source was not shared between household } \\
\text { and herd; trough only indicates only tanker, tap, or well sources were used. }\end{array}$} \\
\hline
\end{tabular}



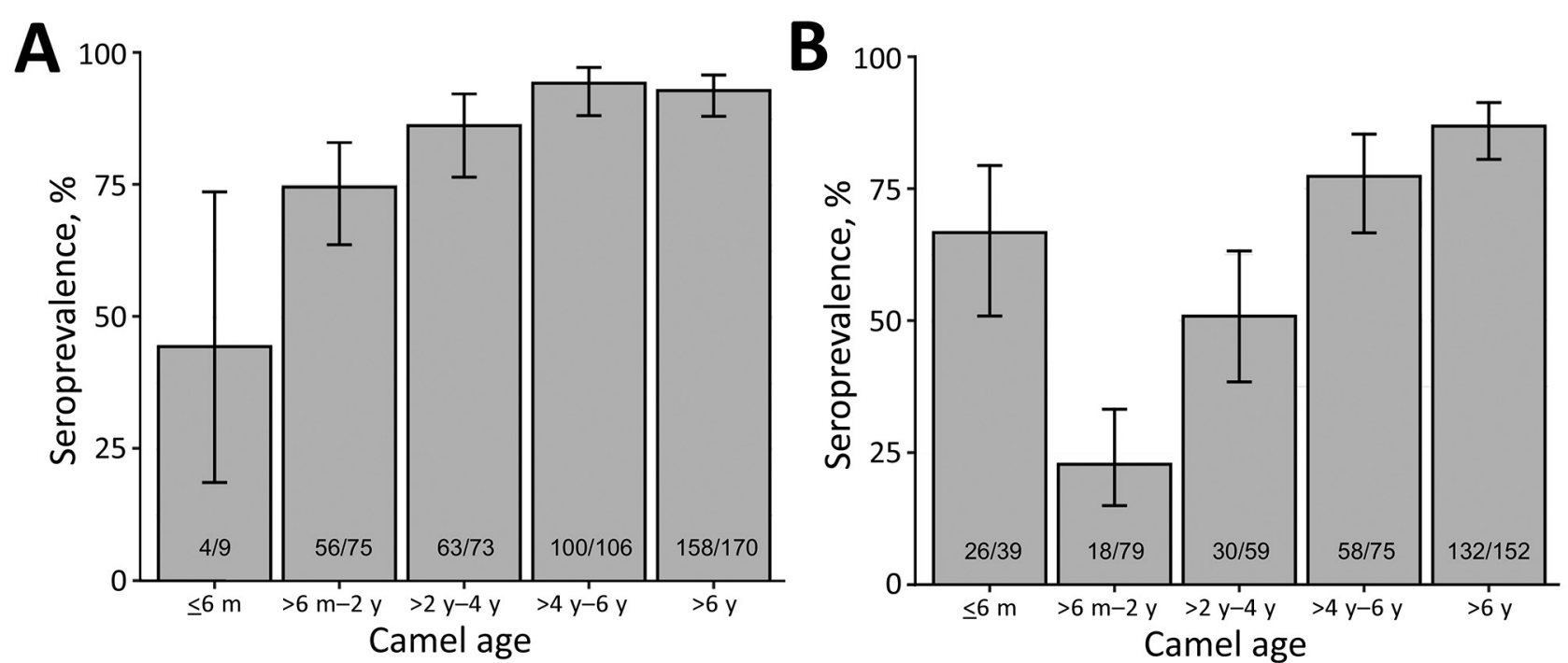

Figure 4. Middle East respiratory syndrome coronavirus seroprevalence among camel population in southern Jordan, stratified by age, February 2014-December 2015 and October 2017-October 2018. A) 2014-2015 study, B) 2017-2018 study. Error bars indicate 95\% Cls. Numbers within gray boxes depict seropositive camels and total number of camels per age group.

MERS-CoV between infected and uninfected camel herds in Jordan. Both studies demonstrated that borrowing camels for breeding was associated with an increase in MERS-CoV seropositivity in receiving herds. In addition, the 2014-2015 study demonstrated that the borrowing of breeding males was a significant risk, whereas the borrowing of breeding females was not (we did not record sex of camels borrowed for breeding in 2017-2018).

In Jordan, as in other countries in the region, many herd owners do not own a breeding male camel because of cost or ease of management; instead, they borrow stud bulls from neighboring herds or send

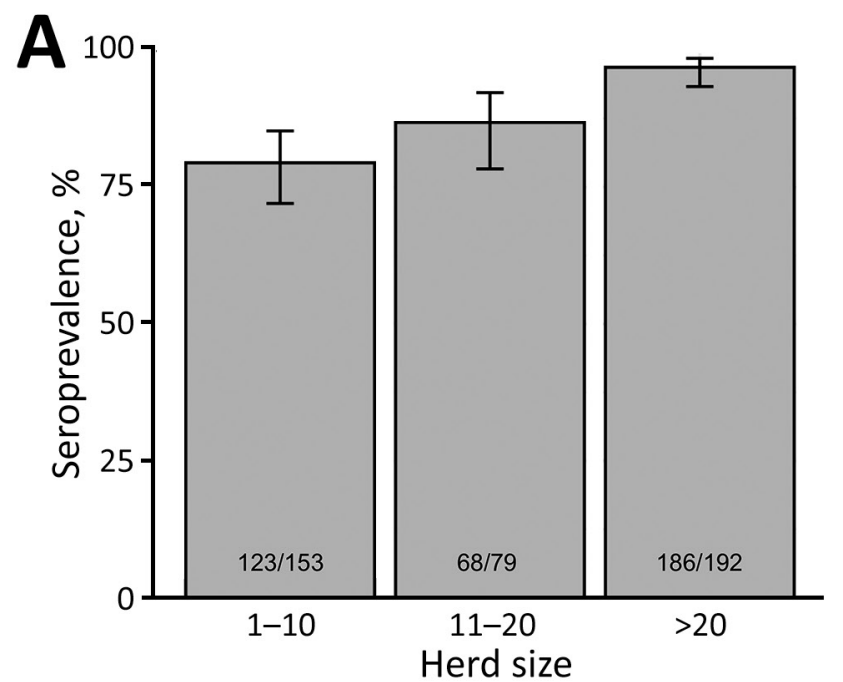

breeding females to herds that have a bull. These practices serve to provide spatial connectivity between infected and uninfected herds; this effect is potentially compounded by the immunosuppressive stresses of transport and joining a new herd and by the effects of male rutting behavior, in which oronasal secretions are sprayed over, or close to, breeding females $(25,26)$.

Given evidence for the potential risk posed by borrowing breeding males, vaccination of male camels shared between herds for breeding could be prioritized when effective camel vaccines become available (18), particularly among small-scale extensively

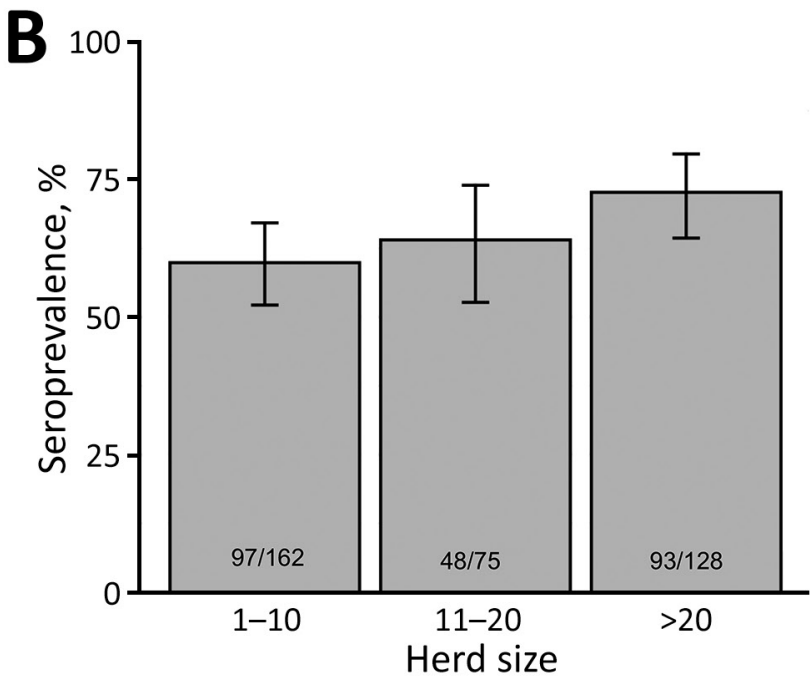

Figure 5. Middle East respiratory syndrome coronavirus seroprevalence among camel population in southern Jordan, stratified by herd size, February 2014-December 2015 and October 2017-October 2018. A) 2014-2015 study; B) 2017-2018 study. Error bars indicate $95 \%$ Cls. Numbers within gray boxes depict seropositive camels and total camels per herd size range. 
Table 4. Multivariate associations between potential risk factors and Middle East respiratory syndrome coronavirus seropositivity in camel populations, southern Jordan, October 2017-October 2018

\begin{tabular}{|c|c|c|c|c|}
\hline Variable* $^{*}$ & A priori adjusted OR $(95 \% \mathrm{Cl}) \dagger$ & $\mathrm{p}$ value & Fully adjusted OR $(95 \% \mathrm{Cl}) \ddagger$ & $p$ value \\
\hline Age, per y§ & $1.60(1.35-1.99)$ & $<0.01$ & $1.60(1.34-1.92)$ & $<0.01$ \\
\hline Camels borrowed for breeding purposes & $4.46(1.29-21.68)$ & 0.03 & $5.07(1.37-18.75)$ & 0.02 \\
\hline \multicolumn{5}{|l|}{ Water sourceף } \\
\hline Open ad lib & Referent & 0.07 & Referent & 0.05 \\
\hline Household only & $3.17(0.44-25.78)$ & & $3.33(0.51-21.71)$ & \\
\hline Trough only & $7.93(1.41-65.04)$ & & $9.48(1.54-58.24)$ & \\
\hline \multicolumn{5}{|l|}{ Region } \\
\hline Ma'an & $3.28(0.92-14.94)$ & 0.08 & $3.83(1.01-14.51)$ & 0.05 \\
\hline \multicolumn{5}{|l|}{ Herd size } \\
\hline Increasing individual camel nos. & $1.02(1.00-1.05)$ & 0.05 & $1.00(1.00-1.05)$ & 0.10 \\
\hline \multicolumn{5}{|l|}{ Sex§ } \\
\hline $\mathrm{F}$ & $1.70(0.59-4.88)$ & 0.32 & $1.38(0.48-3.97)$ & 0.54 \\
\hline \multicolumn{5}{|l|}{ No. camel herds within a 15-min drive } \\
\hline$>20$ & $3.33(0.77-17.53)$ & 0.11 & $2.40(0.53-10.84)$ & 0.25 \\
\hline $\begin{array}{l}\text { Herd is kept together as single group } \\
\text { throughout the year }\end{array}$ & $2.24(0.61 .9 .85)$ & 0.23 & - & - \\
\hline Herd has contact with other local herds & $2.34(0.65-9.85)$ & 0.19 & - & - \\
\hline Camel is a racing camel§ & $0.73(0.13-4.33)$ & 0.72 & - & - \\
\hline Camels are lent for breeding purposes & $2.39(0.66-10.70)$ & 0.19 & - & - \\
\hline Closed herd\# & $0.07(0.01-0.43)$ & 0.01 & $0.08(0.01-0.55)$ & 0.02 \\
\hline \multicolumn{5}{|c|}{$\begin{array}{l}\text { *Variables reference the 1-year period before sampling, with the exception of herd size, camel is a racing camel, and a priori variables: age, sex, and } \\
\text { region. Because of the potential influence of maternal immunity, camels }<6 \mathrm{~m} \text { of age have been excluded. } \\
\text { †Adjusted for a priori variables: age, sex, and region. } \\
\text { †2017-2018 study was adjusted for a priori variables and number of camels nearby (within a } 15 \text { min drive), herd is kept as a single group throughout the } \\
\text { year, herd has contact with other local herds, and camel is a racing camel. } \\
\text { \$lndividual camel-level variables (all other variables being herd-level). } \\
\text { ๆOpen ad lib indicates irrigation reservoir or spring water sources were used; household only indicates water source was not shared between household } \\
\text { and herd; trough only indicates only tanker, tap, or well sources were used. } \\
\text { \#Closed herd indicates herd owners answered no to all of the following variables: borrowing, lending, purchasing, racing, and contact with local or distant } \\
\text { herds ( } 2017-2018 \text { study only, missing data } 2014-2015) \text {. Because of collinearity with constituent variables, the variable closed herd was included in a } \\
\text { separate multivariate model from camels are borrowed for breeding purposes and camels are lent for breeding purposes. In this model, all variables listed } \\
\text { continued to demonstrate significant association ( }<<0.05) \text { with Middle East respiratory syndrome coronavirus seropositivity, with the exception of water } \\
\text { source }(p=0.07) \text {. }\end{array}$} \\
\hline
\end{tabular}

managed herds, such as those in Jordan. In addition, despite the challenges of artificial insemination in camelids, the introduction of an affordable artificial insemination service, where feasible, could mitigate the transmission of MERS-CoV between infected and uninfected herds (27). Other potential control measures could be introducing rRT-PCR testing schemes using nasal swab samples before movement between herds and quarantining of positive animals (28). In view of the current understanding that MERS-CoV transmission in camels occurs primarily through upper respiratory droplet, evidence for possible sexual transmission remains inconclusive, and further research is required $(12,29)$.

Closed herd management practices were found to be significantly protective, offering a potentially valuable tool in controlling MERS-CoV among camels; voluntary closed herd schemes are a possible route to achieving disease-free herds (30). Where such practices would be impractical, our findings suggest that quarantining animals before introduction to the herd offers a protective effect. On the basis of current evidence of viral shedding patterns in camels, quarantine periods of $\geq 2$ weeks should be employed.
Increasing herd size was found to be associated with increased MERS-CoV seroprevalence; larger herds are thought to provide a greater host reservoir capable of sustaining viral transmission between infected and uninfected animals $(16,17)$. In addition, the use of water troughs within herds, as opposed to open ad lib water sources, was associated with increased herd seroprevalence (although only in the 2017-2018 multivariate model when the variable borrowing for breeding was included). Although crowded troughs might be a potential route of viral transmission within herds, further research is required (31).

As described in other studies, seroprevalence increased significantly with age in both studies, likely associated with the increased probability of disease exposure over time and boosting of antibody levels by repeat infections $(16,17)$. Results of the 2017-2018 study strongly suggest the presence of maternally derived immunity among calves $\leq 6$ months of age, which could have relevance for future vaccination strategies (18). This association was less evident in the 2014-2015 study; however, only 9 camels $\leq 6$ months of age were sampled in 2014-2015, compared with 39 in 2017-2018. Associations between sex and seropositive status have been previously described, but 
no significant associations were identified in either study $(16,17,32)$.

The difference in adjusted seroprevalence observed between studies (together with differences in regional associations with seropositivity) might be explained by several factors. Those factors include differences in sampling strategy (nonprobabilistic vs. probabilistic), an absence of sample collection during the 2017-2018 summer period (with seroprevalence highest in summer 2014-2015), and a possibly limited introduction of new MERS-CoV variants into the population between the study periods, with geographic spread over time (33). Importing of foreign camels into Jordan is strictly regulated by MoA and permitted only for animals going directly to slaughter (34).

The first limitation of this study is that no nasal swab specimens tested positive for MERS-CoV RNA on rRT-PCR; evidence for potential viral transmission routes were therefore suggestive instead of definitive. Possible explanations include the narrow window of nasal shedding reported in camels ( $\leq 2$ weeks) (12) and the low prevalence of nasal discharge observed, potentially reflecting a limited genetic diversity of MERS-CoV variants circulating among camels in Jordan with rapid seroconversion and clearance (35). Second, limited sample size resulted in considerable uncertainty on strength of associations. Third, data at the level of individual camels, particularly regarding history of movement for purchase and breeding, were limited. Such data could have supported herd-level findings and identified camels potentially infected outside the herd (depending on duration of detectable antibodies) (36). Fourth, in detecting an association between seropositivity and potential risk factors, assumptions were made regarding persistence of detectable antibodies ( $>1$ year), meaning that estimates of association are potentially conservative $(37,38)$.

In conclusion, borrowing male camels for breeding and closed herd management practices were associated with MERS-CoV infection prevalence among camel populations in Jordan, suggesting possible useful interventions to reduce transmission. In addition, older age, larger herd size, and use of water troughs within herds were also associated with seropositivity. In view of this finding, future MERS-CoV vaccination strategies among camel populations in Jordan could potentially prioritize breeding males, which are likely to be shared between herds for breeding purposes. In addition, several targeted management interventions should be considered: measures to reduce the number of camels, particularly males, shared between herds for breeding purposes (including, if feasible, introducing an affordable camel artificial insemination service at a regional or national level); maintaining a closed herd where possible, including the potential for voluntary closed herd management schemes; and quarantine practices of $\geq 2$ weeks before introducing new animals to the herd. The implementation of such interventions among herds in Jordan and the wider region, alongside targeted vaccination, could reduce the prevalence of MERS-CoV among camel populations and confer a vitally protective effect on human populations associated with these herds (39).

\section{Acknowledgments}

We sincerely thank the Ministry of Agriculture in Jordan, Fares A. Altakhainah, Ghassab H. Hasanat, Hassan H. Alhusainat, Zaidoun S. Hijazeen, Abdalmajeed M. Alajlouni, and Hani A. Talafha.

This research was supported by a Medical Research Council Global Challenges Research Fund Foundation award (2017-2018 study) and a Foreign and Commonwealth Office Bilateral Programme Budget Fund award from the British Embassy in Amman (2014-2015 study). N.vD., M.L. and V.J.M. are supported by the Division of Intramural Research of the National Institute of Allergy and Infectious Diseases, National Institutes of Health.

\section{About the Author}

Dr. Holloway is a researcher with the Royal Veterinary College, London. His primary research interest is the epidemiology and control of camel zoonoses.

\section{References}

1. Peeri NC, Shrestha N, Rahman MS, Zaki R, Tan Z, Bibi S, et al. The SARS, MERS and novel coronavirus (COVID-19) epidemics, the newest and biggest global health threats: what lessons have we learned? Int J Epidemiol. 2020;49:717-26. https://doi.org/10.1093/ije/dyaa033

2. European Centre for Disease Prevention and Control. Severe respiratory disease of unknown origin - Jordan outbreak in ICU. Communicable Disease Threats Report, Week 18, 29 April-5 May, 2012 [cited 2021 May 19]. https:/ / www.ecdc.europa.eu/sites/default/files/media/ en/publicationsPublications/CDTR $\% 20$ online $\% 20$ version $\% 204 \% 20$ May $\% 202012$.pdf

3. Lucey DR. Editorial commentary: still learning from the earliest known MERS outbreak, Zarqa, Jordan, April 2012. Clin Infect Dis. 2014;59:1234-6. https:/ / doi.org/10.1093/ cid/ciu638

4. World Health Organization. Middle East respiratory syndrome [cited 2021 May 19]. http:/ / www.emro.who.int/ health-topics/mers-cov/mers-outbreaks.html

5. Reusken CB, Ababneh M, Raj VS, Meyer B, Eljarah A, Abutarbush S, et al. Middle East Respiratory Syndrome 
coronavirus (MERS-CoV) serology in major livestock species in an affected region in Jordan, June to September 2013. Euro Surveill. 2013;18:20662. https:// doi.org/10.2807/1560-7917. ES2013.18.50.20662

6. Azhar EI, El-Kafrawy SA, Farraj SA, Hassan AM, Al-Saeed MS, Hashem AM, et al. Evidence for camel-tohuman transmission of MERS coronavirus. N Engl J Med. 2014;370:2499-505. https:// doi.org/10.1056/NEJMoa1401505

7. Lau SKP, Zhang L, Luk HKH, Xiong L, Peng X, Li KSM, et al. Receptor usage of a novel bat lineage $\mathrm{C}$ betacoronavirus reveals evolution of Middle East respiratory syndromerelated coronavirus spike proteins for human dipeptidyl peptidase 4 binding. J Infect Dis. 2018;218:197-207. https://doi.org/10.1093/infdis/jiy018

8. World Health Organization. Middle East respiratory syndrome coronavirus (MERS-CoV) [cited 2021 May 19]. https://www.who.int/news-room/fact-sheets/detail/ middle-east-respiratory-syndrome-coronavirus-(mers-cov)

9. Dudas G, Carvalho LM, Rambaut A, Bedford T. MERS-CoV spillover at the camel-human interface. [Erratum in: Elife. 2018;7:e37324]. eLife. 2018;7:e31257.

10. Assiri A, McGeer A, Perl TM, Price CS, Al Rabeeah AA, Cummings DA, et al.; KSA MERS-CoV Investigation Team. Hospital outbreak of Middle East respiratory syndrome coronavirus. N Engl J Med. 2013;369:407-16. https:/ / doi.org/ 10.1056/NEJMoa1306742

11. Cho SY, Kang JM, Ha YE, Park GE, Lee JY, Ko JH, et al. MERS-CoV outbreak following a single patient exposure in an emergency room in South Korea: an epidemiological outbreak study. Lancet. 2016;388:994-1001. https:/ / doi.org/ 10.1016/S0140-6736(16)30623-7

12. Adney DR, van Doremalen N, Brown VR, Bushmaker T, Scott D, de Wit E, et al. Replication and shedding of MERS-CoV in upper respiratory tract of inoculated dromedary camels. Emerg Infect Dis. 2014;20:1999-2005. https://doi.org/10.3201/eid2012.141280

13. Alnaeem A, Kasem S, Qasim I, Al-Doweriej A, Al-Houfufi A, Alwazan A, et al. Some pathological observations on the naturally infected dromedary camels (Camelus dromedarius) with the Middle East respiratory syndrome coronavirus (MERS-CoV) in Saudi Arabia 2018-2019. Vet Q. 2020;40:1907. https:/ / doi.org/10.1080/01652176.2020.1781350

14. Hui DS, Azhar EI, Kim YJ, Memish ZA, Oh MD, Zumla A. Middle East respiratory syndrome coronavirus: risk factors and determinants of primary, household, and nosocomial transmission. Lancet Infect Dis. 2018;18:e217-27. https://doi.org/10.1016/S1473-3099(18)30127-0

15. World Health Organization. Prioritizing diseases for research and development in emergency contexts [cited 2021 May 19]. https:/ / www.who.int/activities/ prioritizing-diseases-forresearch-and-development-in-emergency-contexts

16. Dighe A, Jombart T, Van Kerkhove MD, Ferguson N. A systematic review of MERS-CoV seroprevalence and RNA prevalence in dromedary camels: implications for animal vaccination. Epidemics. 2019;29:100350. https://doi.org/10.1016/j.epidem.2019.100350

17. Sikkema RS, Farag EABA, Islam M, Atta M, Reusken CBEM, Al-Hajri MM, et al. Global status of Middle East respiratory syndrome coronavirus in dromedary camels: a systematic review. Epidemiol Infect. 2019;147:e84. https://doi.org/ 10.1017/S095026881800345X

18. Alharbi NK, Qasim I, Almasoud A, Aljami HA, Alenazi MW, Alhafufi A, et al. Humoral immunogenicity and efficacy of a single dose of ChAdOx1 MERS vaccine candidate in dromedary camels. Sci Rep. 2019;9:16292. https:/ / doi.org/ 10.1038/s41598-019-52730-4
19. Rodon J, Okba NMA, Te N, van Dieren B, Bosch BJ, Bensaid A, et al. Blocking transmission of Middle East respiratory syndrome coronavirus (MERS-CoV) in llamas by vaccination with a recombinant spike protein. Emerg Microbes Infect. 2019;8:1593-603. https:/ / doi.org/10.1080/ 22221751.2019.1685912

20. Adney DR, Wang L, van Doremalen N, Shi W, Zhang Y, Kong WP, et al. Efficacy of an adjuvanted Middle East respiratory syndrome coronavirus spike protein vaccine in dromedary camels and alpacas. Viruses. 2019;11:212. https:// doi.org/10.3390/v11030212

21. Mubarak A, Alturaiki W, Hemida MG. Middle East respiratory syndrome coronavirus (MERS-CoV): infection, immunological response, and vaccine development. J Immunol Res. 2019;2019:6491738. https://doi.org/10.1155/2019/6491738

22. van Doremalen N, Hijazeen ZS, Holloway P, Al Omari B, McDowell C, Adney D, et al. High prevalence of Middle East respiratory coronavirus in young dromedary camels in Jordan. Vector Borne Zoonotic Dis. 2017;17:155-9. https://doi.org/10.1089/vbz.2016.2062

23. Falzarano D, Kamissoko B, de Wit E, Maïga O, Cronin J, Samaké K, et al. Dromedary camels in northern Mali have high seropositivity to MERS-CoV. One Health. 2017;3:41-3. https://doi.org/10.1016/j.onehlt.2017.03.003

24. Corman VM, Eckerle I, Bleicker T, Zaki A, Landt O, Eschbach-Bludau M, et al. Detection of a novel human coronavirus by real-time reverse-transcription polymerase chain reaction [Erratum in: Euro Surveill. 2012;17:pii/20288]. Euro Surveill. 2012;17:20285. https:// doi.org/10.2807/ ese.17.39.20285-en

25. Saeb M, Baghshani H, Nazifi S, Saeb S. Physiological response of dromedary camels to road transportation in relation to circulating levels of cortisol, thyroid hormones and some serum biochemical parameters. Trop Anim Health Prod. 2010;42:55-63. https://doi.org/10.1007/s11250-009-9385-9

26. Padalino B, Monaco D, Lacalandra G. Male camel behaviorand breeding management strategies: how to handle a camel bull during the breeding season? Emir J Food Agric. 2015;27:338-49. https://doi.org/10.9755/ ejfa.v27i4.19909

27. Skidmore JA, Morton KM, Billah M. Artificial insemination in dromedary camels. Anim Reprod Sci. 2013;136:178-86. https://doi.org/10.1016/j.anireprosci.2012.10.008

28. Al Hammadi ZM, Chu DK, Eltahir YM, Al Hosani F, Al Mulla M, Tarnini W, et al. Asymptomatic MERS-CoV infection in humans possibly linked to infected dromedaries imported from Oman to United Arab Emirates, May 2015. Emerg Infect Dis. 2015;21:2197-200. https:/ / doi.org/ 10.3201/eid2112.151132

29. Hemida MG, Waheed M, Ali AM, Alnaeem A. Detection of the Middle East respiratory syndrome coronavirus in dromedary camel's seminal plasma in Saudi Arabia 20152017. Transbound Emerg Dis. 2020;67:2609-14. https://doi.org/10.1111/tbed.13610

30. Sayers RG, Sayers GP, Mee JF, Good M, Bermingham ML, Grant J, et al. Implementing biosecurity measures on dairy farms in Ireland. Vet J. 2013;197:259-67. https:/ / doi. org/10.1016/j.tvj1.2012.11.017

31. Fèvre EM, Bronsvoort BM, Hamilton KA, Cleaveland S. Animal movements and the spread of infectious diseases. Trends Microbiol. 2006;14:125-31. https://doi.org/10.1016/ j.tim.2006.01.004

32. Kandeil A, Gomaa M, Nageh A, Shehata MM, Kayed AE, Sabir JSM, et al. Middle East respiratory syndrome coronavirus (MERS-CoV) in dromedary camels in Africa and Middle East. Viruses. 2019;11:717. https://doi.org/10.3390/v11080717 
33. Wernery U, Woo PCY. Middle East respiratory syndrome: making the case for surveillance of transboundary coronaviruses in the Middle East. Rev Sci Tech. 2019;38:61-9. https://doi.org/10.20506/rst.38.1.2941

34. Abutarbush S, Hijazeen Z, Doodeen R, Hawawsheh M, Ramadneh W, Al Hanatleh M. Analysis, description and mapping of camel value chain in Jordan. Glob Vet. 2018;20:144-52.

35. Seifert SN, Schulz JE, Ricklefs S, Letko M, Yabba E, Hijazeen ZS, et al. Limited genetic diversity detected in Middle East respiratory syndrome-related coronavirus variants circulating in dromedary camels in Jordan. Viruses. 2021;13:592. https://doi.org/10.3390/v13040592

36. Ali MA, Shehata MM, Gomaa MR, Kandeil A,

El-Shesheny R, Kayed AS, et al. Systematic, active surveillance for Middle East respiratory syndrome coronavirus in camels in Egypt. Emerg Microbes Infect. 2017;6:e1. https://doi.org/10.1038/emi.2016.130

37. Hemida MG, Alnaeem A, Chu DK, Perera RA, Chan SM, Almathen F, et al. Longitudinal study of Middle East
Respiratory Syndrome coronavirus infection in dromedary camel herds in Saudi Arabia, 2014-2015. Emerg Microbes Infect. 2017;6:e56. https:// doi.org/10.1038/emi.2017.44

38. Wernery U, Corman VM, Wong EY, Tsang AK, Muth D, Lau SK, et al. Acute Middle East respiratory syndrome coronavirus infection in livestock dromedaries, Dubai, 2014. Emerg Infect Dis. 2015;21:1019-22. https:/ / doi.org/10.3201/ eid2106.150038

39. Al-Ahmadi K, Alahmadi M, Al-Zahrani A. Spatial association between primary Middle East respiratory syndrome coronavirus infection and exposure to dromedary camels in Saudi Arabia. Zoonoses Public Health. 2020;67:382-90. https://doi.org/10.1111/zph.12697

Address for correspondence: Peter Holloway, Veterinary Epidemiology, Economics and Public Health Group, The Royal Veterinary College, Royal College St, London NW1 0TU, UK; email: pholloway3@rvc.ac.uk
- Coordinated Strategy for a Modeling-Based Decision Support Tool for COVID-19, Utah, USA

- Clinical Laboratory Perspective on Human Infections Caused by Unusual Nonhemolytic, Lancefield Group B Streptococcus halichoeri

- Case Series of LaboratoryAssociated Zika Virus Disease, United States, 2016-2019

- Successful Control of an Onboard COVID-19 Outbreak Using the Cruise Ship as a Quarantine Facility, Western Australia T

- Coccidioidomycosis and COVID-19 Co-Infection, United States, 2020

- Epidemiologic Findings From Case Investigations and Contact Tracing of the First 200 Cases of Coronavirus Disease 2019 Identified in Santa Clara County, California, USA

- SARS-CoV-2 in Nursing Homes after 3 Months of Serial, Facility-Wide Point Prevalence Testing, Connecticut, USA

- Herd Immunity against Severe Acute Respiratory Syndrome Coronavirus 2 Infection in 10 Communities, Qatar

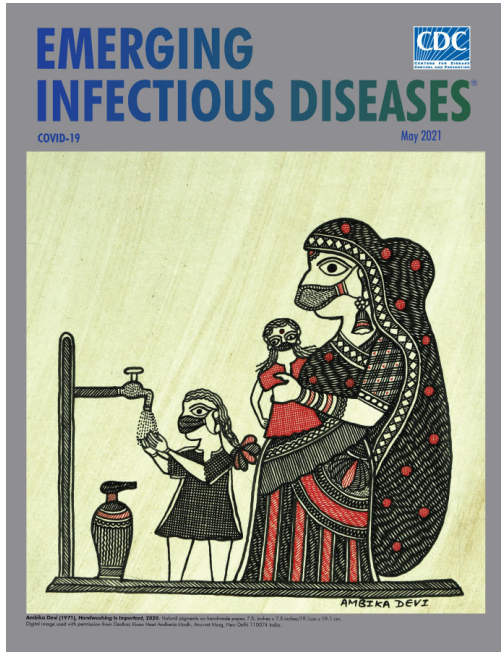

- Engineered NS1 Provides Sensitive and Specific Zika Diagnosis from Patient Serology

- Transmission of Severe Acute Respiratory Syndrome Coronavirus 2 during Border Quarantine and Air Travel, New Zealand (Aotearoa)

- Characteristics and Clinical Implications of CarbapenemaseProducing Klebsiella pneumoniae Colonization and Infection, Italy
- Symptom Diary-Based Analysis of COVID-19 Disease Course, Germany, 2020

- Use of Genomics to Track Coronavirus Disease Outbreaks, New Zealand

- Serologic Screening of Severe Acute Respiratory Syndrome Coronavirus 2 Infection in Cats and Dogs during First Coronavirus Disease Wave, the Netherlands

- Epidemiologic History and Genetic Diversity Origins of Chikungunya and Dengue Viruses, Paraguay

- Monitoring SARS-CoV-2 Circulation and Diversity through Community Wastewater Sequencing, the Netherlands and Belgium

- Active Case Finding of Current Bornavirus Infections in Human Encephalitis Cases of Unknown Etiology, Germany, 2018-2020

- Susceptibility to SARS-CoV-2 of Cell Lines and Substrates Commonly Used to Diagnose and Isolate Influenza and Other Viruses

- Global Trends in Norovirus Genotype Distribution among Children with Acute Gastroenteritis 